\title{
DEIXIS, CUERPO E INTEMPERIE: LA GRAMÁTICA DEL NUEVO COMPROMISO POÉTICO EN ERIKA MARTÍNEZ
}

Deixis, body and homelessness: the grammar of the new poetic commitment in Erika Martínez

\section{JAVIER MOHEDANO RUANO}

UNIVERSIDAD DE CóRDOBA(ESPAÑA) jmohedano.averroes@gmail.com

RECIBIDO: 5 DE FEBRERO DE 2018

ACEPTADO: 18 DE ABRIL DE 2018

RESUMEN: El vaciamiento semántico de la noción de compromiso literario exige una revisión crítica en momentos en que las relaciones entre poesía y antagonismo vuelven a prestigiarse. Tras un examen sintético de la génesis y canonización del concepto, se propone la lectura del último poemario de Erika Martínez como ejemplo del vínculo fructífero entre cuerpo, paisaje y política. A partir de los conceptos de presencia y territorialización, se defiende la tesis de que la nueva poesía política pasa por la impugnación de la dicotomía sujeto-objeto y por el cultivo de una inteligencia sensitiva que reconecte vida y mundo y permita, desde la crítica y el escepticismo, recobrar las riendas de la historia individual y colectiva. De este modo, el compromiso deja de estar alojado en la conciencia del yo autorial para anidar en el corazón mismo del poema.

PALABRAS CLAVE: poesía, compromiso, política, deixis, paisaje, cuerpo.

ABSTRACT: The semantic emptying of the notion of literary commitment demands a critical revision at a time when the relations between poetry and antagonism become prestigious again. After a synthetic examination of the genesis and canonization of the concept, the reading of Erika Martínez's last book of poems is proposed as an example of the fruitful link between body, deixis and politics. From the concepts of presence and territorialisation, the article argues that new political poetry needs the challenge of the subject-object dichotomy and the cultivation of a sensitive intelligence that reconnects life and world and allows, from the criticism and skepticism, to regain the reins of individual and collective history. Therefore, commitment is no longer housed in the consciousness of the authorial self. Now it nests in the heart of the poem.

KEYWORDS: poetry, commitment, politics, deixis, landscape, body.

Mohedano Ruano, Javier.

“Deixis, cuerpo e intemperie: la gramática del nuevo compromiso poético en Erika Martínez”.

Kamchatka. Revista de análisis cultural 11 (Julio 2018): 311-330

DOI: 10.7203/KAM.11.11470 ISSN: 2340-1869

Monográfico LECTURAS DEL DESIERTO: NUEVAS PROPUESTAS POÉTICAS EN ESPAÑA 


\section{FIGURACIONES Y FANTASMAGORÍAS DEL COMPROMISO LITERARIO.}

Debate, ideología, retórica... Solemnes palabras, palabras que fundan una comunidad y sus límites. Palabras que, sin embargo, sustraídas transitoriamente de la circulación pragmática, realojadas en el espacio aséptico de una sala de exposiciones, se muestran alarmantemente vacuas, terriblemente frágiles. De ahí su progresiva disolución, su degradación hasta la condición de ruido. Estas imágenes, tomadas de la exposición Palabras, palabras de Antoni Muntadas en la Galería Moisés Pérez de Albéniz de Madrid en 2017, bien podrían haber incluido el tan manoseado -por defensores y detractores- concepto de compromiso, cuya rehabilitación en el parnaso patrio concita una sospechosa unanimidad en la que quizás se confundan tentativas sinceras de reactivación del binomio arte y política con estrategias oportunistas de reubicación en un campo literario enormemente convulso y volátil. La pregunta es, por tanto: ¿asistimos al saludable desbordamiento de las coordenadas convencionales del compromiso o, por el contrario, a su parasitación y clausura en este tiempo obsesionado por monumentalizar? Sin negar lo segundo, preferimos sondear las posibilidades de ese desborde apuntado en la primera de las opciones a través de la mirada de la poeta Erika Martínez (Jaén, 1979), que precisamente afirma en su último poemario, Chocar con algo, que "aquello que rebasa concierne a la lírica" (Martínez, 2017: 18), un sobrepasar los límites convencionales de la literatura política que no niega su tradición, sino que la lleva más lejos: "Más allá del tradicional compromiso, y salvando las muy legítimas excepciones, creo que la ética de la poesía actual se articula como crítica. No hay relativismo en ella: la crítica es también un ejercicio de responsabilidad” (Martínez, 2013b: 51).

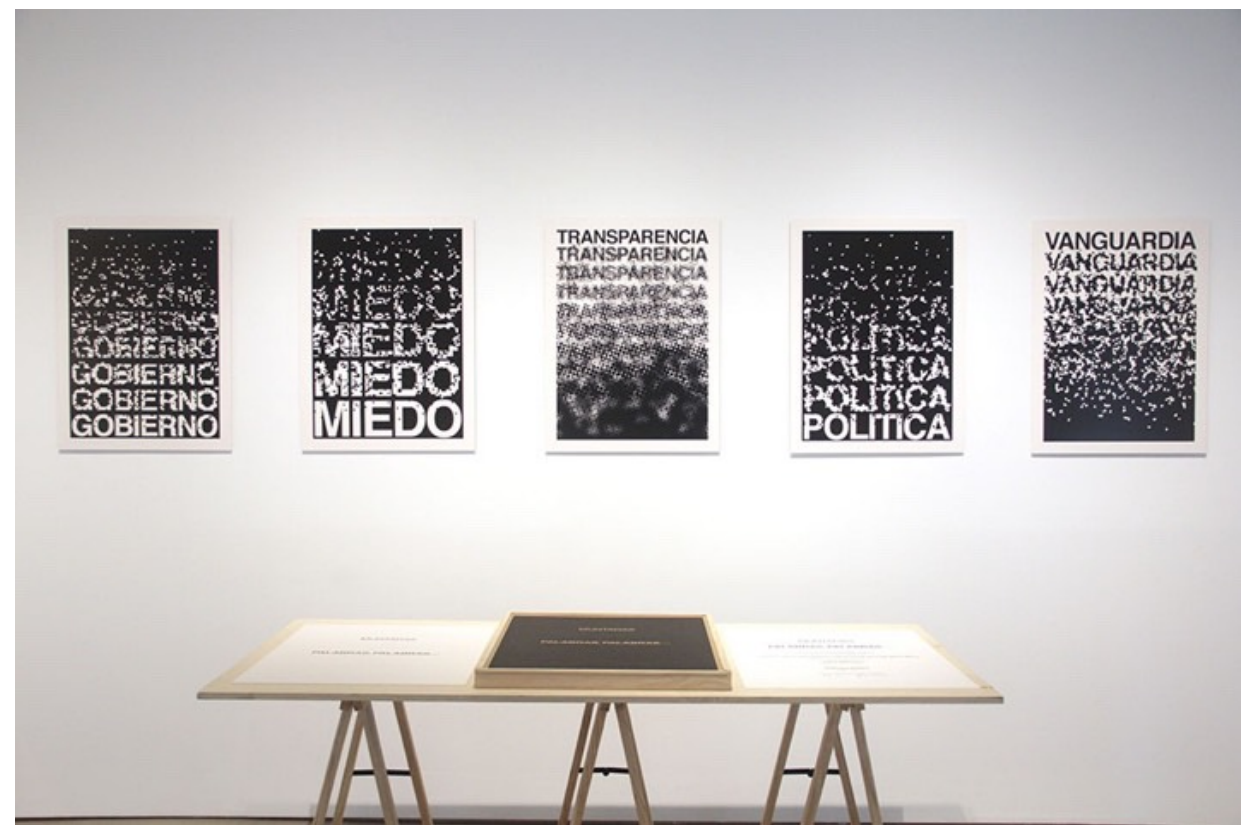

Palabras, palabras. Antoni Muntadas, 2017.

Pero antes de centrarnos en la obra de Martínez, la creciente visibilidad de las estéticas antagonistas en la poesía española reciente requiere de un desbroce crítico y de una actualización del término y de las plurales prácticas a él asociadas, con el fin de evitar el doble precipicio al que suelen asomarse temerariamente las polémicas académicas al uso: o el de calificar a toda literatura de comprometida, por el hecho de constituir un objeto social, además de textual, imposible de 
sustraer de su contexto histórico (por mor de una heteronomía radical todo discurso sería, deliberadamente o no, testimonio de su tiempo y, por ende, político); o, por reacción y desde una celebración también extrema de la autarquía artística, el de negar cualquier virtualidad política a una creación literaria que debiera atenerse al universo paralelo y trascendente por y para ella instituido, bien sea desde la celebración de un formalismo de estirpe greenbergiana, bien sea desde la reclusión en una suerte de mindfulness lírico en el que la pretendida atención plena a lo íntimo (o a sus pecios) se alcanza desde la mutilación o negación del mundo.

Aunque no es el propósito de este artículo la radiografía de la literatura crítica reciente en torno a la noción de compromiso estético, sí que, sin ánimo de ser exhaustivos, unas cuantas catas se bastan para evidenciar que conviven en nuestro panorama investigador propuestas en las que no están reñidos el rigor, la voluntad clarificadora y el antidogmatismo con otras que, aunque bien intencionadas, desdibujan tanto el concepto de compromiso que, de tan generoso e inclusivo, acaba por no decir nada, o decirlo todo. Así, Luis Bagué Quílez subraya la pluralidad de una literatura comprometida marcada por la "ampliación del acervo retórico (desde la serenidad clásica al metaforismo vanguardista)" y por "cierta heterogeneidad temática" en consonancia con "un receptor más complejo" y un mundo que ha dejado atrás la política de bloques (Bagué Quílez, 2006: 341); Araceli Iravedra distingue entre "un discurso lírico ocasionalmente escorado hacia la esfera de «lo civil», que puede integrarse en el poema como uno entre otros de los desvelos temáticos de su creador" y otros, los que realmente pueden calificarse de comprometidos, "que reconocen abiertamente su naturaleza política o, cuando menos, aceptan su articulación radical con la sociedad y la historia y la difuminación de los contornos de lo privado y lo público" (Iravedra, 2010: 19); Alberto García-Teresa destaca entre los rasgos que delimitan la poesía de la conciencia crítica "una explícita condena de los engranajes del capitalismo", "una actitud vitalista", una relación distinta con el lenguaje y la mirada, la ausencia de "todo tipo de paternalismo", la "búsqueda de lo colectivo", la naturalidad en el tratamiento de las contradicciones y fracasos, o el vínculo indisoluble con la veridicción (García Teresa, 2013: 37-55); Miguel Ángel García advierte de que el "compromiso de los poetas no depende exactamente de su responsabilidad moral, de sus buenas intenciones sociales o de sus tomas de decisión políticas", sino que se ubica en "las relaciones entre literatura e ideología, entendida esta en sentido althusseriano" (García, 2017: 9-10); y Remedios Sánchez García, por finalizar este muestreo con un ejemplo de la generosidad arriba apuntada, celebra un compromiso que, reducido a "Voz social de alarma ante la opresión [...] partiendo de principios éticos y comprometidos con el momento concreto en que surge para ser útil a la sociedad", propicia una supuesta reconciliación de las familias poéticas españolas gracias a un Humanismo Solidario que pone la lírica al servicio de la "fraternidad universal” (Sánchez García, 2014: 53, 61). 


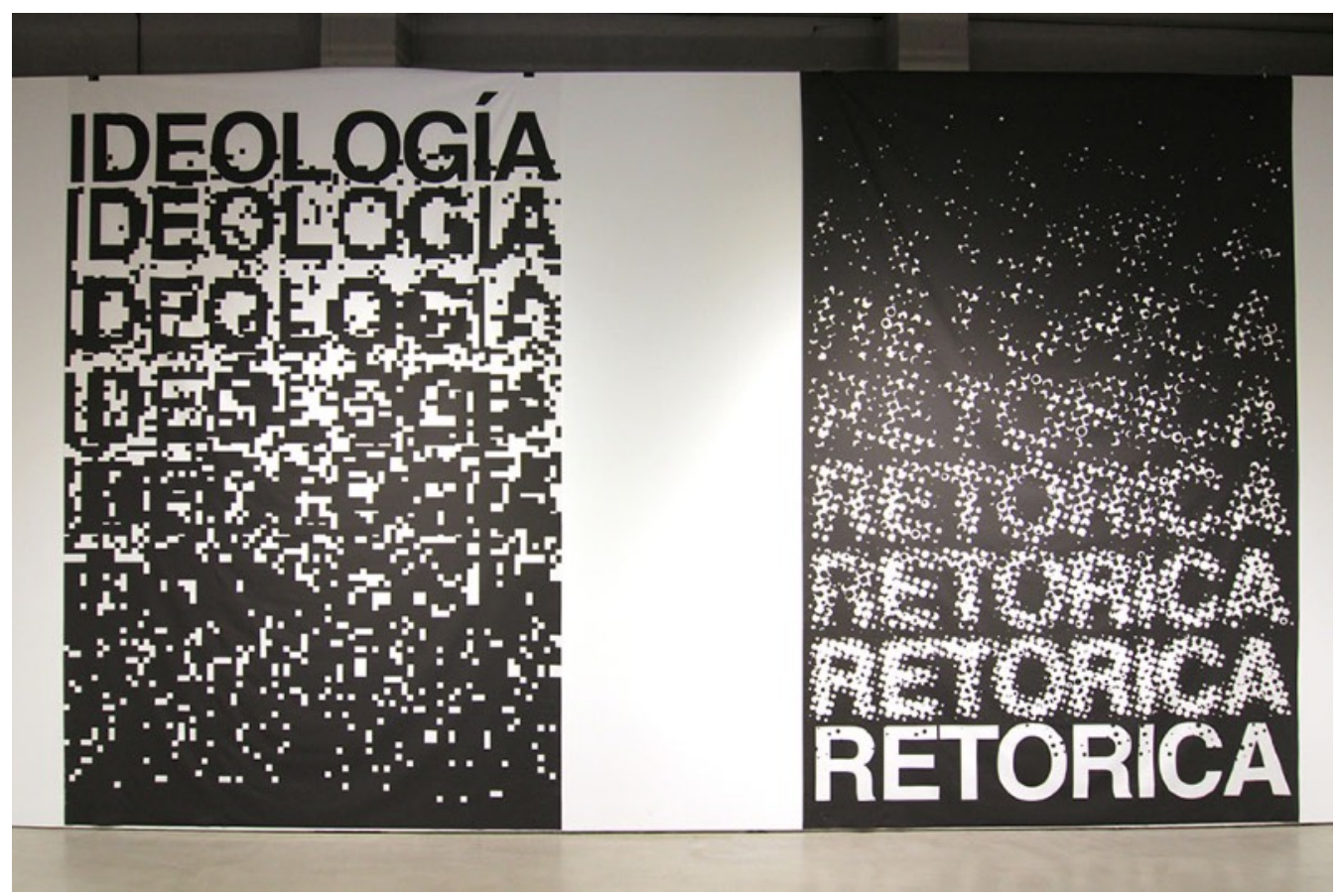

Palabras, palabras. Antoni Muntadas, 2017

Si alguien representa bien tanto la ruptura con la antaño monotonía crítica que había presidido los estudios sobre el compromiso, como el diagnóstico certero de prácticas literarias antagonistas que van más allá del gesto intelectual o la indignación inoperante es Antonio Méndez Rubio, responsable de algunas de las aproximaciones al concepto más clarividentes y estimulantes de nuestro panorama académico. En la colección de ensayos que conforman La destrucción de la forma ( $Y$ otros escritos sobre poesía y conflicto), Méndez Rubio parte de la génesis y consolidación del canon de la poesía política fijado por Jan Lechner en su ya clásico El compromiso en la poesía española del siglo XX para prestar atención precisamente a lo que se descarta, a la geografía en sombra de aquellas experiencias que se han negado o menospreciado por el mero hecho de emborronar la pretendida linealidad y solidaridad del compromiso en nuestra lírica. En el preámbulo de su estudio Lechner, tras recorrer la genealogía del término, reconoce que se trata de un asunto "vidrioso" y que "en cada época el compromiso en poesía se constituye de forma distinta, brota de otros supuestos y tiene otras particularidades", concluyendo con una provisional, tautológica e insatisfactoria definición, que tiene más de claudicación que de conquista: "Por poesía comprometida española entendemos la escrita en español por poetas españoles residentes en su propio país y conscientes de su responsabilidad como miembros de la sociedad y como artistas y que asumen conscientemente las consecuencias de esta actitud, tanto en el terreno civil como en el literario" (Lechner, 2004: 49-50). Si bien ya en esa vaga proposición emergen algunos prejuicios epistemológicos significativos (los juegos binarios ciudadano-artista, sociedad civil-comunidad literaria), es en el relato histórico de Lechner, que comienza en 1898 y finaliza en los albores de la década de los 70, donde los ingredientes de un modo concreto de concebir el compromiso comparecen y se hacen explícitos: de una parte, un realismo más o menos tamizado por la memoria, la intimidad y la reflexión (en su acepción menos problematizadora, la que presupone una correa de transmisión natural entre lenguaje y mundo); y, de otra parte, un humanismo de raigambre orteguiana en el que las intenciones (la potencia 
aristotélica) tienen más valor que su concreción textual, dado que se insiste en el mantra de la diversidad de estilos y versificación. Lo fundamental parece ser siempre algo anterior al texto, que lo presupone sin necesidad de que deje huella en él: "la reflexión sobre el papel del escritor en la sociedad y un acercamiento a lo que constituye la base de cualquier arte: el hombre" (ibidem: 242). Un reconocible precedente del Humanismo Solidario antes reseñado.

Como diagnostica certeramente Méndez Rubio, las limitaciones que ofrece la conceptualización de Lechner son palmarias: reducir toda figuración de lo real a su incuestionado y mimético reflejo excluye, por supuestamente evasivas, las propuestas experimentales y de vanguardia, que no constituyen una negación de toda representación, sino solo de aquellas naturalizadas que obvian que no hay mirada desinteresada; y subordinar el debate estético y retórico a una ética meramente declarativa, de la que emanaría espontáneo e inmotivado su trasunto verbal, degrada el lenguaje a la condición de medio aséptico, simple canal de una conciencia autosuficiente, dócil metal moldeable en manos del poeta orfebre:

La materialidad lingüística del poema ocupa el último lugar, un lugar subordinado a la conciencia y la acción de los poetas, en primer lugar, y a la confrontación con una determinada realidad, positivamente reconocible, en segundo [...], de donde se sigue que el lenguaje (en la línea de Sartre, pero en contraste con la «conciencia práctica» de la que hablaron Marx y Engels en La ideología alemana) es determinado por (pero no determinante de) el grado de compromiso de esa poesía, o de ese poeta. [...] [E]l lenguaje es concebido como un fenómeno derivado de una realidad a priori, siendo ésta identificable y reconocible por la conciencia de un sujeto fuerte, centrado, entero, que a su vez constituye esa realidad dotándola de un orden delimitable y objetivo (Méndez Rubio, 2013: posiciones 1576-1578 y 1629-1631 en edición digital de Kindle).

Como afirma Méndez Rubio, lo que lastra el canon de Lechner es precisamente lo que no se pone en tela de juicio, el denominado "punto ciego" epistemológico que asume como universal indubitable la dicotomía racionalista de sujeto -"la necesidad de una conciencia, intención o voluntad que gobierna el trabajo lingüístico y lo somete a sus designios"- y objeto - "un entorno y a la vez un trasfondo que la conciencia subjetiva refleje y sobre el que esa conciencia se proyecte, en fin, bajo la forma de una realidad determinada, reconocible de forma positiva"- (ibidem: posición 1608-1610 en edición digital de Kindle). Por consiguiente, para superar las restricciones de las premisas de Lechner y dar respuesta a un "fascismo de baja intensidad", que deviene "una totalización mercantil de lo posible", debieran activarse, si se sigue esta línea argumental, "una noción materialista de lenguaje como práctica social y no como sistema o código meramente abstracto" y, por ende, modos de representación crítica "que asumen que lo visible y los parámetros de la Realidad sólo son cuestionados cuando son traspasados" (ibidem: posición 1616-1623). 


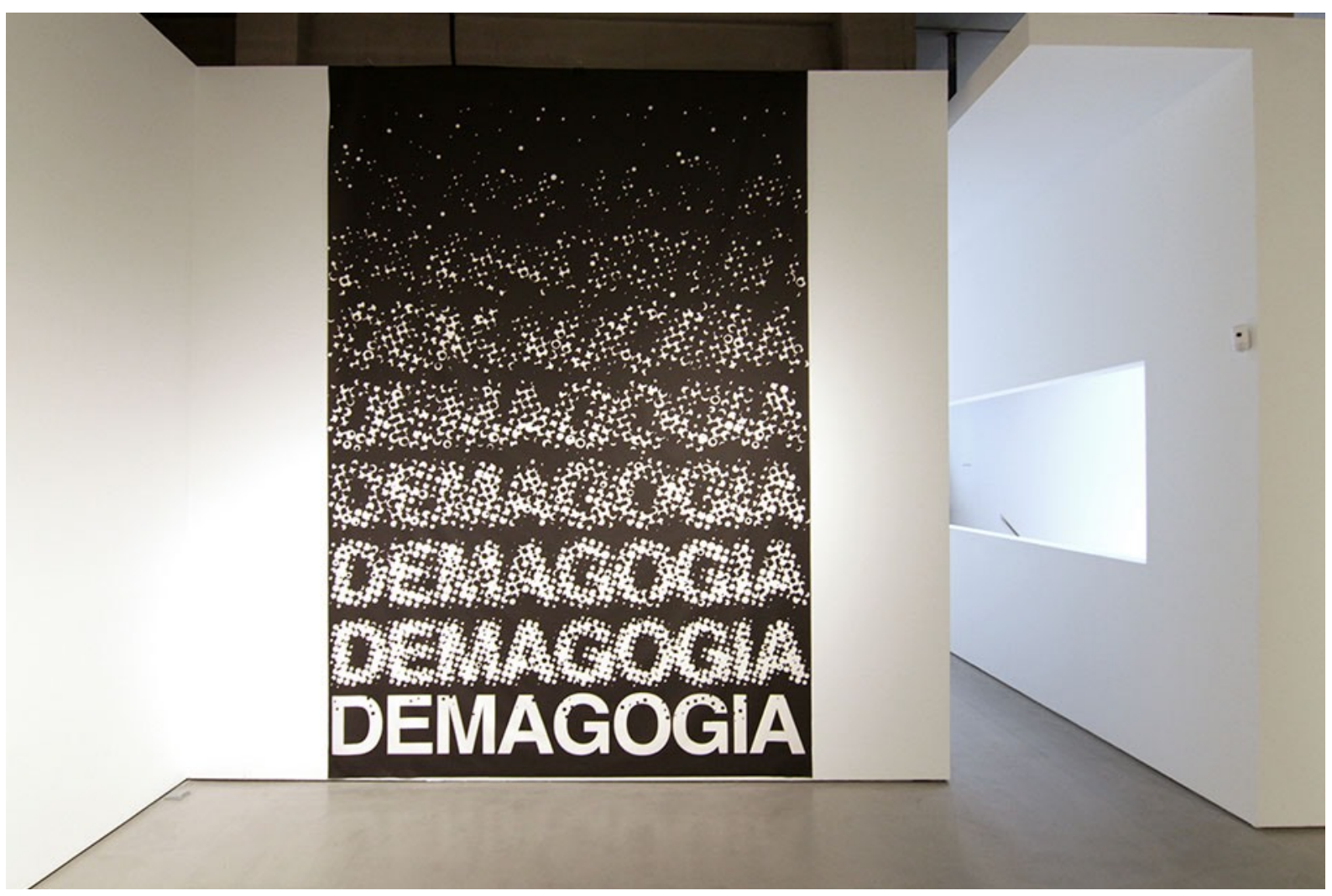

Palabras, palabras. Antoni Muntadas, 2017

La revolución invisible desde realismos limitrofes de Méndez Rubio, en la "que la tensión lingüística (del lenguaje como «conciencia práctica») entra en contacto con su alteridad, con su otredad oscura, con la zona de sombra que desestabiliza su posición como criterio de unificación y solidificación de la experiencia individual y colectiva" (ibidem: posición 2115-2116 en edición digital de Kindle) no está lejos de los planteamientos de los filósofos Miguel Benasayag y Angélique del Rey. En su ensayo El compromiso en una época oscura proponen una reformulación del concepto que parte de las siguientes premisas:

- El compromiso ha estado lastrado por el asimétrico esquema cartesiano res cogitans/res extensa, de modo que cuando se hablaba de liberar al mundo, en el fondo se trataba de salvar al sujeto racionalista. El modelo del activista de raigambre ilustrada es Robinson Crusoe: dadme una isla salvaje, plagada de caníbales, y os devolveré un Estado de Derecho.

- Por consiguiente, "la transformación del mundo no es el resultado de un plan previo establecido desde una posición de exterioridad" (Benasayag y del Rey, 2014: 11) y superioridad. Hay que desechar la emancipación tal y como la ha entendido el progresismo humanista, como proyección de lo esencial humano sobre una realidad reducida a mero decorado estático.

- Dado que los sujetos no son algo exterior al mundo, sino "producto (y co-productores) del mismo", (ibidem: 13) "el punto de partida no puede situarse en el sujeto, sino en el mundo, [...] entendido como un conjunto ilimitado de relaciones" (ibidem: 11), como paisaje en el que no cabe "una escisión clara entre un «adentro» y un «afuera» [...]. Lo único que existe es el «adentro», [...] una realidad múltiple y conflictiva que va definiéndose 
por la tensión inmanente de las multiplicidades y las fuerzas en desequilibrio inestable que la componen" (ibidem: 13).

- Con el fin de corregir las tendencias idealizantes del compromiso clásico, que buscan "evadirse de las dimensiones espacio-temporales de la existencia" (ibidem: 18), hay que apostar por la territorialización, que "es el medio de recuperar las conexiones que nos componen, y [es] el desarrollo de las conexiones [...] el comienzo del compromiso" (ibidem: 19).

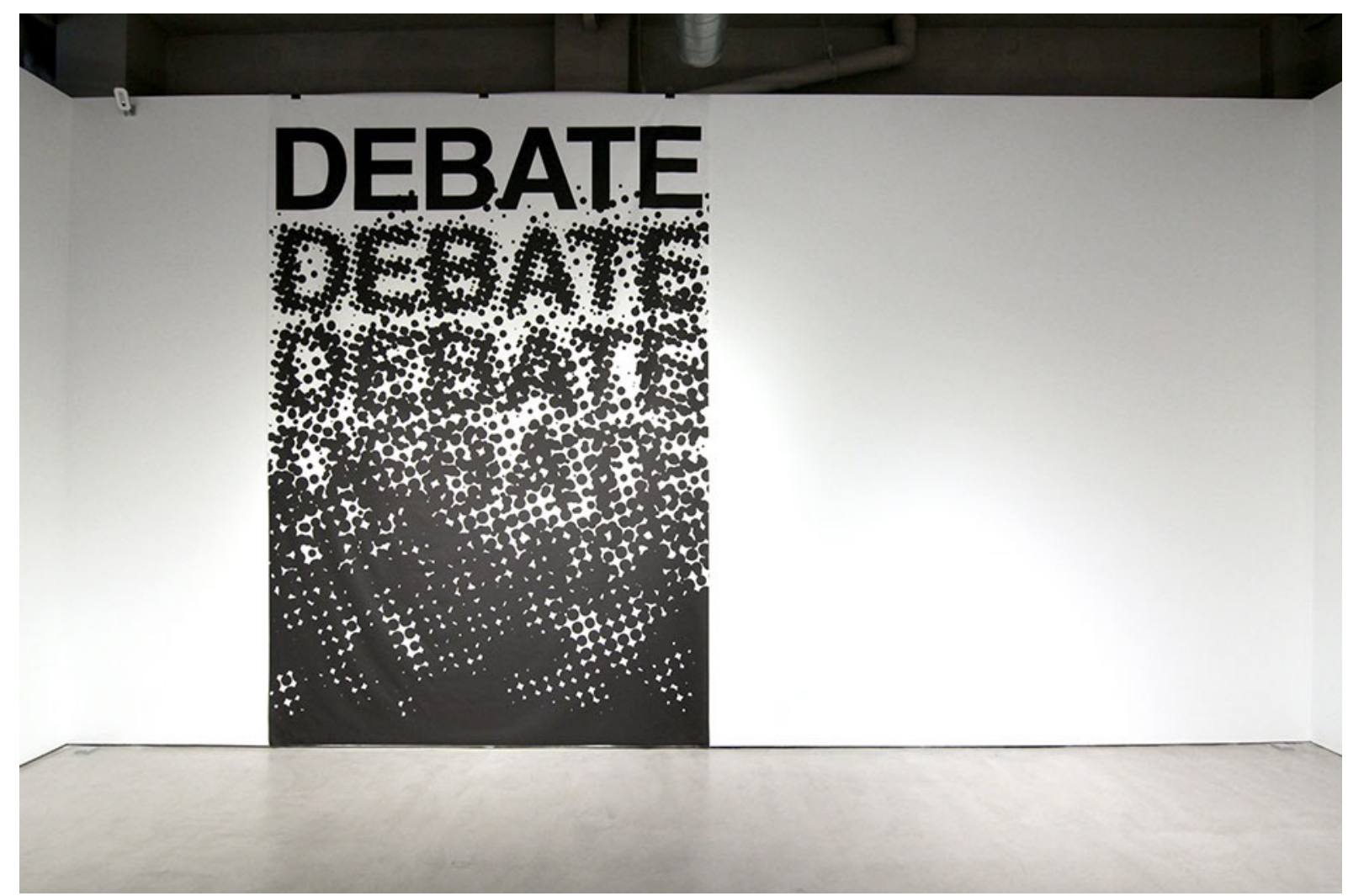

Palabras, palabras. Antoni Muntadas, 2017

Esta concepción relacional y contextual del compromiso persigue, en definitiva, superar la impotencia en la que se halla sumido el sujeto crítico contemporáneo: en un mundo que tiende a lo virtual y a lo desenraizado, "nos sentimos impotentes, separados de nosotros mismos, evolucionando en la vida sin cuerpo, sin ataduras, sin territorios, al tiempo que sufrimos la imposibilidad de intervenir en el curso del mundo y en nuestra propia vida" (ibidem: 64).

Como puede observarse, las concomitancias entre estos postulados y los antes presentados de Méndez Rubio son evidentes. Ambos tratan de armar alternativas a la triple crisis que socava los pilares sobre los que se asentaba tradicionalmente el compromiso literario: en primer lugar, la crisis de legitimación de la voz enunciadora, esto es, la dificultad de tomarse en serio el éthos autorial (en el doble sentido ético - paradigma intersubjetivo de valores y hábitos- y retórico -la proyección pública en la escritura de esa modulación del yo-) tras las sucesivas muertes y resurrecciones del sujeto; en segundo lugar, la crisis de lo real y su formalización/comunicación, en esta época nuestra de pantallización y evanescencia, mediación y disolución de las fronteras entre representación y objeto representado, y consolidación de la hipóstasis y de la ecdótica como 
paradigmas de vida; y, por último, la crisis de lenguaje (qué puede decirse en la cultura de la sospecha propiciada por la deslegitimación de los relatos públicos, la posverdad y las fake newss).

Esta operación de resemantización de las prácticas literarias antagonistas puede enmarcarse, además, en el impulso más amplio y ambicioso de rescate y rehabilitación de la crítica como lugar desde el que mirar y decir que nos legó la Ilustración, pero en todo su esplendor germinal, sin los corsés del programa modernizador capitalista que, como apunta la filósofa Marina Garcés, han terminado por lastrar su potencia disruptiva: el "universalismo expansivo" del humanismo "eurocéntrico y patriarcal"; el "analfabetismo ilustrado", o la fractura entre conocimiento y transformación del mundo; el encapsulamiento de los discursos de las Humanidades, degradados a la condición de disciplinas "cerradas y autorreferentes", de "meros conocimientos de textos sobre textos"; o la "estandarización" de lenguajes y saberes, en un paradigma civilizatorio en el que la acumulación de información, inocua por saturación e indigestión, ya no guarda solidaridad con aspiración emancipadora alguna, con la consecución de una "vida vivible" (Garcés, 2017: 59-74).

Pergeñado el estado de la cuestión en torno a las insuficiencias del relato habitualmente legitimado de compromiso estético, y apuntados así mismo algunos itinerarios que permitirían su revitalización en la actual coyuntura histórica y literaria, corresponde ahora aterrizar en la concreción de los textos, con el fin de evaluar si ese sujeto que renuncia a su pretendida posición de privilegio y que contrae una obligación moral con un mundo del que es parte indivisible, y desde una voluntad que se desea, ante todo, "situacional y concreta", de intervención en unos territorios que "constituyen nuestras superficies de afectación" (Benasayag y del Rey, 2014: 59, 64), realmente ha encontrado eco en la poesía española reciente.

Y creemos, y esta es la hipótesis que se tratará de demostrar a continuación, que Erika Martínez ejemplifica bien un compromiso de nuevo cuño que, asentado en una mirada analítica nada indulgente, en la investigación y en la territorialización, aventura un rearme de la poesía política que recorra el camino que va de la conciencia crítica (catarsis interior que ha de ser traducida en acciones y que a menudo está al servicio no de la intervención en lo real, sino de la reafirmación de un sujeto paralizado en la elegía) a la presencia crítica ("estado de una cosa que se halla delante de otra u otras o en el mismo sitio que ellas", según el Diccionario de la lengua española de la RAE, un saberse en el mundo entre otros sin jerarquías). El tránsito de conciencia a presencia crítica lo posibilita la noción de paisaje, esto es, territorio observado, que desarticula el binomio sujetoobjeto desde un do ut des que reivindica la circunstancia como forja de una voz lírica no solipsista, entretejida en la textura de lo real, extrovertida en su sentido más literal. Y esa nueva relación con los paisajes (el de la intimidad, el del género, el doméstico, el de la esfera pública) requiere de un cuerpo en actitud de escucha y contagio, pasando así de una estética intelectualista e idealista, ocupada en la criba y comunicación de universales que, ajenos a la historia y sus servidumbres, levitan indiferentes a la espera de su captura, a otra sensibilista y trasegadora. La noción de paisaje invita, además, a superar la parcelación y segmentación de saberes que denunciara Garcés y a adoptar una pluralidad de enfoques epistemológicos (desde la geohistoria a los estudios visuales, pasando por la filosofía estética o la teoría queer o cyborg del feminismo más inconformista). Así la lectura crítica acompaña, siempre un paso por detrás, al quehacer poético objeto de análisis en su ejercicio de descentramiento de la mirada, de enmarañamiento con lo supuestamente impropio o 
ajeno y de cuestionamiento de tópicos e imperativos, cuales "tejedoras insumisas, incrédulas y confiadas a la vez" (Garcés, 2017: 75).

PRECARIEDAD Y VULNERABILIDAD EN EL HOGAR, EN EL CUERPO, EN LA PALABRA: EL COMPROMISO OBLICUO DE ERIKA MARTÍNEZ

Aunque nos ocuparemos más extensamente del último de los poemarios de Martínez, es ineludible repasar la arquitectura solidaria de su escritura, de modo que pueda constatarse que la gramática del compromiso que aquí sugeriremos no es accidental o pasajera, sino resultado de un compromiso-investigación (tomamos la afortunada expresión de Benasayag y del Rey) en los que el descreimiento preventivo, la cuarentena contra los asideros sobre los que solía erigirse el edificio lírico (sujeto y mundo, con la palabra como mediadora fiable) es condición inexcusable para la religación con la realidad, en una doble lucha contra la abstracción y la irrelevancia de la comunicación poética en su deriva autorreferencial.

En Color carne (2008) son ya legibles las líneas programáticas de la praxis de Erika Martínez. De una parte, un sujeto poético desorientado, sin asideros: ni la identidad de género heredada, ni la palabra, ni el mundo son espacios de seguridad y certeza. La aventura humanista del yo metamorfosea en un vagar incierto y sin hoja de ruta por el páramo (o la escombrera) de la modernidad (la familia, el hogar, el logos, la identidad). Sin embargo, esta trashumancia obligada (o nómada, como diría la propia Martínez) no deviene esclerosis, sino que acrecienta la curiosidad por un mundo que, no pudiendo ser ya decorado o alfombra roja de un yo expansivo, se revela en toda su opulencia y estimula otros modos de relación: "El conflicto es mi única verdad, / la memoria una sombra que me guía. / Más allá de este bípedo ideal / necesito desorden, / carne asombrada, dulce adrenalina. / [...] Es mía esta palabra a la deriva”, en A LA DERIVA (45).

De otra parte, sobre la crisis de las coordenadas fundacionales de la subjetividad, genealogía de una individualidad desamparada y descreída de sí, se aprecia una tendencia antimetafísica ("Enfrente de las cosas sólo escucho", en PERVERSO POLIMORFO, 17), la determinación de decir desde lo sensitivo ("acompaña mis pasos más alegres / el bastón de lo sensitivo", en INSPIRACIÓN 27), la de hablar con los pies en el suelo, la de no dar por válida la fractura entre sujeto y mundo y la tradición consiguiente de erigirse en individuo desde la renuncia y el despojamiento (la autonomía como cercenadura, o como ensimismamiento). Habitando la paradoja, el reverso de la certidumbre y del imperio de la lógica, la voz lírica hace de la intemperie, o de la tara, su guarida: "Su cabecita descarriada / no logra comprender la diferencia / moral, táctil / que hay entre el yo y el mundo; / busca y empieza a ser pero se desparrama / en todo lo que anhela, [...] / Un día dejará de hacerlo, perderemos algo. / El presente se hará pequeño en mi cubil. / Yo será yo y el mundo, / quién sabe entonces qué será del mundo", en LA TARTAMUDA (19).

En Lenguaraz (2011), el diario intermitente de un yo desahuciado deja paso al aforismo, en un golpe de timón que encamina la dicción lírica a texturas más meditativas y distantes, en una maniobra que previene contra cualquier atisbo de confesionalismo. A este respecto, Javier Moreno, a propósito de lo que denomina (post)presocratismo de la poesía española actual, recuerda que "aforismo tiene su origen etimológico en apo horizein ('delimitar', 'proponer un horizonte'), 
algo que tiene que ver sin duda [...] con la cuestión de la medida y la parcelación (del pensamiento, de las sensaciones y de los sentimientos)" (Moreno, 2013: 237). El aforismo sería entonces limbo o interregno, territorio fronterizo o de tregua en el que idea y sensación, razonamiento e intuición, se acompañan sin recelo, como en los albores de la filosofía occidental, cuando logos y mito, distancia y asombro, habitaban las mismas palabras y constituían experiencias mestizas del mundo: "Los ejemplos golpean al pensamiento abstracto. El aforismo es su hematoma", se afirma en el poemario (76). Si en Color carne la imagen que se nos devuelve del sujeto enunciador es fragmentaria, un puzle al que le faltan demasiadas piezas, en Lenguaraz es el discurso el que comparece desde su deliberada y deseada precariedad, despojado de cualquier afán de sistematicidad, totalización o completitud: es ahora el lenguaje el que se encuentra a la intemperie.

Por otra parte, en este libro se hace aún más evidente el deseo de esbozar un pensamiento háptico, radicalmente sensorial y anticartesiano, una poética diaspórica y centrífuga en la que pensamiento y sensibilismo, introspección y apertura a lo otro aparecen reconciliados. Aforismos tales como "Somos capaces de sentir con cada parte del cuerpo. Quisiéramos poder pensar de esa manera" (15); "Pensar con los ojos, ver hacia el pensamiento" (31); "Atravesar un desierto es un ejercicio espiritual, subir a una cumbre un ejercicio pasional, perderse en un bosque un ejercicio de introspección" (33); "En cada objeto un ser, nunca al contrario" (43); "Hay quien dice esencia donde sólo es posible confirmar persistencia" (52); "Escribir es un acto. Escribir bien, una acción", (60); "La ficción se produce en condiciones materiales y tiene efectos materiales. No es ni verdadera ni falsa, es cierta" (63); "Lo que perdura en los templos egipcios no son los faraones sino las palabras que los nombran sobre la piedra" (69); o "En los fragmentos se ensambla un naturalismo más hondo" (75), desgranan un programa de escritura modulado por principios como el pensamiento encarnado, la aproximación lateral y titubeante a lo real como principio epistemológico, el desbroce de los vínculos entre intimidad y alteridad, la naturaleza performativa de la escritura, la condición radicalmente histórica y matérica de la creación o la estética de la esquirla como antídoto contra el afán totalizante del pensamiento categórico convencional.

Este pensamiento no exento (tomamos la expresión de la propia Martínez) o situacional se torna ejemplo y experiencia en El falso techo (2013), en el que el centro de atención y la voluntad de deconstrucción y controversia se desplazan del sujeto (el eje de Color carne) y el discurso (motivo de despojamiento y reseteo en Lenguaras) a los objetos, al universo material. Se invierte así la lógica racionalista: el sujeto parece subsidiario, continuo solidario, de un mundo objetual descrito como ecosistema dinámico y empático. Paradójicamente (o no, si se ha estado atento al itinerario de Martínez), es la dilución del sujeto en la cosa, la renuncia consciente a la mirada cenital del empirismo más tosco y simplificador, obstinado en reducir lo múltiple a la Forma, la que permite una percepción más amplia, profunda y certera de una realidad poliédrica: "Soy miope. Ahora veo", se afirma en VEO-VEO (43). Descartada cualquier veleidad idealista o mística, el yo poético busca refugio en el reflejo o huella que las cosas le devuelven de sí: "Escribir es hacerle cosquillas / a las raíces de las cosas", en DECIR (41). Abolida la frontera entre afuera y adentro, somos los espacios que habitamos, los objetos que creemos poseer y que también nos poseen. De ahí que sea la prótesis, híbrido entre sujeto y materia, argamasa indistinguible del yo y lo otro, la condición idónea para la veridicción: "Esta es mi tara: uso muletas / para llegar a los objetos / que todo lo contienen", en PORQUE NO ALCANZO (57). 
Es entonces la asunción de la condición de cyborg, concepto fetiche del feminismo y del poshumanismo, de la imposibilidad de discernir hoy entre hombre y máquina, entre lo vivo y lo inerte, una ocasión no para cantos apocalípticos de deshumanización, sino para ensayar fórmulas inéditas de humanidad. Lo objetual es, en suma, posibilidad de (auto)reflexión: son las cosas el sustrato del pensamiento, y no a la inversa.

\section{VOLVERSE PAISAJE: PRESENCIAS Y LATENCIAS EN CHOCAR CONALGO}

El último poemario de Erika Martínez, Chocar con algo, publicado en 2017, ilustra sobradamente aquel compromiso-investigación que ha tomado cuerpo desde Color carne y que vendría a sustituir el compromiso trascendente o humanista, desde "la aceptación del mundo tal y como es", con todo su abigarramiento, feliz desorden y resistencia feroz a cualquier empeño clasificador, en la certeza de que lo real "no existe concretamente más que bajo una multiplicidad de formas diversas, variadas y contradictorias, es decir, en cada «singularidad»", y de que, por consiguiente, no puede concebirse "de una manera separada, al margen del conocimiento y de la acción” (Benasayag y del Rey, 2014: 47, 53).

Desde las primeras páginas de Chocar con algo se pone de manifiesto la naturaleza deíctica de la escritura ("se escribe siempre desde algún lugar", se dice en MUJER ADENTRO, 11), el desbordarse de un poema que se resitúa entre las cosas del mundo y adquiere valor en tanto que ocupa un espacio y un momento singulares. El texto, desde el prestigio de una vocación referencial no estigmatizadora, convoca a las cosas, que comparecen en toda su plenitud e irreductibilidad matérica, y no como símbolos o pretextos para ejercicios de mística verbal, restituyéndose así el equilibrio entre palabra y objeto. El poema ni preconfigura lo real (idealismo), ni lo rehúye desde la prestidigitación metalingüística o intimista: es un estar-y-hacer-enel-mundo. Este desplazamiento desde la autonomía (palabra sin mundo) a la heteronomía (palabra en el mundo) del discurso queda patente en los versos de ESTACIÓN (59):

Antes pensaba que escribir era sinónimo de acción y ahora sospecho que se escribe después de un tiempo inmóvil, quizás desde el vacío que sucede a un excesivo estar haciendo.

$[\ldots]$ Ni una cosa ni la otra: escribir concierne al tránsito, enfermedad, paseo, duermevela.

Y en VISITANTE (67) se insiste en el rechazo de un poema desarraigado, autotélico y complaciente:

Le pregunto al hombre que barre si me deja barrer. Hay cosas que se aprenden ensuciándose. ¿O será que exageramos lo inapelable de la experiencia? Creí que todo intento de comprobación debía suceder dentro del poema; que la poesía era su propio acontecimiento. Nunca sé cuándo me engaño. 
En la visión prehistórica del mundo, reinaba lo poroso. Las categorías hombre, mujer, animal o piedra eran intercambiables, y no había barreras entre necios y santos. La poesía es protohistórica y es siempre la circunstancia.

Atiéndase a varios aspectos: el deseo de enfangarse y perder el estatuto inmaculado del sujeto suficiente (acertada la metáfora del barrendero: la atalaya ascética del poeta social deja paso a un punto de vista no cenital, precario, mundano); la añoranza por una continuidad cosmogónica casi totémica, una suerte de solidaridad paradigmática en el que todo ser podía ocupar el lugar de otro, en un tiempo casi mítico en el que aún no había irrumpido el logos categorizador y sistemático de los helenos; y, sobre todo, la más que significativa oposición que se establece entre historia y circunstancia. Si la primera ha tendido a concebirse, desde la linealidad del relato del Progreso y de la emancipación del Espíritu, como el cumplimiento de una promesa mesiánica, la consecución de la misión autoimpuesta en la Ilustración, la segunda, a menudo vilipendiada, constituye una vindicación de otras modulaciones y vivencias de lo temporal. Así, la rehabilitación de la circunstancia, que remite a lo que de accidental (de deíctico, de coyuntural, de relacional, de singular) hay en cada ser, pero también al "conjunto de lo que está en torno a alguien" (de nuevo acudimos a las palabras del DLE de la Real Academia Española), es decir, a la toma de conciencia del paisaje del que formamos parte y que nos limita y des-limita al tiempo, abre la puerta a un giro epistemológico en el que la óntica, el estar en el mundo, reemplaza a la fijación ontológica, esencialista, hegemónica en nuestra tradición filosófica occidental.

El poema se convierte de este modo en escuela de una sensibilidad incardinada e incardinadora, abierta a la percepción desprejuiciada de una realidad proteica y transustancial, en la que una mirada no lastrada por lo conceptual apriorístico o por el fervor taxonómico deconstruye la perspectiva lineal sobre la que nos alertó Panofsky ("No se puede mantener la perspectiva. / Si pones el ojo en la cerradura, / te devuelve la mirada" en MIRAR A TRAVÉS, 62). También es capaz de reintegrarnos una experiencia de lo temporal en la que el pasado, rescatado de la labor reificadora y musealizadora de la teleología histórica, aguarda larvado, preñado de futuro, en el presente ("Lo que suena abre un agujero donde asoma / el bosquecillo impúdico de lo posible", de EL ÚlTIMO DEMAGOGO, 58; o "Aunque apenas ocurrió, todo insiste / simultáneo con leve impertinencia", de SINCRONÍAS, 49), y recuerda a la imagen dialéctica de Walter Benjamin, aquella "en donde lo que ha sido se une como un relámpago al ahora en una constelación” (Benjamin, 2011: 464).

La irrupción de la presencia en el poema (esa presencia crítica que ha de suceder a la conciencia para que comparezca la política, la palabra acción) alumbra una latencia, un tiempo en espera de ser despertado, activado, por un yo poético que ha subvertido las relaciones convencionales con los objetos, con el paisaje: "De lo que hicimos / queda el lugar / [...]. La historia cruje" (47). En línea con las tesis defendidas por el filósofo e historiador del arte Georges Didi-Huberman, uno de los continuadores de la imagen cargada de tiempo de Benjamin, ya no es sostenible la mirada del sujeto de la Modernidad, que toma del mundo sólo aquello que desea ver y que encuentra cabida en esquemas previos, aquello que le reafirma en su posición de superioridad epistemológica y ontológica: "Acabo de romper con una piedra / la pantalla narcótica del agua” (34). La percepción se problematiza, se vuelve dialéctica, porque las cosas nos 
devuelven una mirada desasosegante y estimulante a la vez: "el acto de ver nos abre a un vacío que nos mira, nos concierne y, en cierto sentido, nos constituye" (Didi-Huberman, 1997: 15).

Ese vacio que nos concierne adopta la forma de intemperie en Erika Martínez. Intemperie significa aquí paisaje sin domesticar, en la doble acepción del término: espacio que se resiste a ser reabsorbido por lo doméstico, a ser antropomorfizado, como si de un decorado se tratara, de una parte; y espacio que conserva sus aristas, su aspereza, esto es, su condición de radical otro, de otra: "Los museos exponen la intemperie bajo techo. / Al final prefieres mirar: detrás de las cristaleras, los pájaros se / caen del cielo y el hombre que barre se los lleva del patio" (72). Sin embargo, esta experiencia desconcertante (la de una conciencia que, acostumbrada a mirar para instituirse en el espejo-mundo, se da de bruces con la fisicidad indomeñable de las cosas) no desemboca en nihilismo, en un canto fúnebre por la expropiación de los antes vastos dominios de la subjetividad: el paisaje ha dejado de ser prolongación simbolista de un yo enfermo de bybris ("Los deseantes desvanecemos el mundo / para permanecer, es detestable", 53) para revelarse como bullente biotopo en el que las cosas interaccionan entre sí y con la voz enunciadora en una relación paratáctica, alejada de cualquier anhelo subordinante o colonizador. No se renuncia a la formalización textual de la persona, a su emersión como sujeto de enunciación, pero se ensayan fórmulas de distanciamiento y cuestionamiento que, sin caer en el simulacro de la impersonalidad (la objetividad, el sueño empírico de comunicar el mundo como si no se estuviese, es tan impostada como el egotismo), permitan dibujar una singularidad dicente dialógica. Salvo, eso sí, que identifiquemos impersonalidad y corporeidad: "lo que es sagrado en el cuerpo humano no es núcleo personal sino, al contrario, el impersonal, [...] lo que está más allá, pero también más acá de la persona" (Simone Weil, citada por Esposito, 2016: 104-105).

En esa nueva cartografía de lo subjetivo, en la que se reivindica la ligazón cortocircuitada por el Humanismo entre ente que mira y ente mirado ("Los españoles somos criaturas / precartesianas", Martínez 2017: 13), el cuerpo se hace paisaje, desde una concepción cuasi geológica de lo humano que persigue una desarticulación de la perspectiva artificialis antes señalada. Esa paisajización o voluntad de constituirse y pensarse como lugar ("Un paisaje cubierto de huellas dactilares", ibidem: 43) permite una redefinición permeable y migrante del yo (territorialización lo denominaban Benasayag y del Rey, recordemos), una reinserción de hombres y mujeres en sus contextos (en sus circunstancias) desde un ejercicio de des-antropomorfización del mundo objetual que ilumina posibilidades vitales inéditas. La elusión de lo humano como medida y estética de todas las cosas y la irrupción de lo matérico no accesorio y sometido desalambran la percepción y nos devuelven una imagen poliédrica del yo en el mundo. Si hasta el momento "las personas han sido definidas, sobre todo, por el hecho de no ser cosas" y "la relación entre ellas es de dominación instrumental, en el sentido de que el rol de las cosas es servir o al menos pertenecer a las personas" (Esposito, 2016: 21-22), Erika Martínez deshace este reparto de papeles e invalida estos principios limitadores (somos y estamos en-y-entre cosas), llegando incluso en algunos poemas a invertir los términos: son las personas las que pertenecen a los objetos, las que necesitan de ellos para ser y estar. Los objetos, al igual que el cuerpo, nos reingresan en el mundo, constituyen una invitación a desestimar los cantos de sirena de una vida diferida y subrogada, aplazada por lo evanescente virtual de una poshumanidad ubérrima y eterna, sin anclajes ni paisajes. 
Ha de advertirse, no obstante, que la territorialización o paisajización de Martínez no puede entenderse como una cosificación de lo humano. En compañía aún del filósofo Roberto Esposito, Martínez lucha al tiempo contra "la despersonalización de las personas" (vía tentaciones ultramundanas, espirituales o virtuales) y "la desrealización de las cosas" ("reducida a la idea o la palabra", o a la mercancía en el ámbito económico). ¿Desde dónde? Desde el cuerpo, "lugar sensible donde las cosas parecen interactuar con las personas" (Esposito, 2016: 8), "el canal de tránsito y el operador [...] de una relación cada vez menos reducible a una lógica binaria" (ibidem: 9), como lugar mixto que "no coincide ni con la persona ni con la cosa, [...] ajena a la escisión que cada una de ellas proyecta sobre la otra" (ibidem: 15).

La centralidad del cuerpo conjura entonces cualquier veleidad metafísica y asume la doble función que le encomendara la tradición fenomenológica: "llenar el hueco en los seres humanos entre logos y bios", de un lado, y "restituir al objeto intercambiable su carácter de cosa singular", de otro (ibidem: 16). De esta manera, "es como si las cosas, cuando están en contacto con el cuerpo, adquirieran ellas mismas un corazón que las reconduce al centro de nuestra vida. Cuando las salvamos de su destino serial y las reintroducimos en su escenario simbólico, nos damos cuenta de que son parte de nosotros no menos de lo que nosotros somos parte de ellas" (ibidem: 16). Recuerda poderosamente esta celebración de una materialidad no subsidiaria a las palabras que Pere Salabert dedica al pintor Zhu Jinshi y su técnica Thick Paint (pintura gruesa):

Su obra constituye una suerte de devolución. [...] [A]l privilegiar una mirada háptica, una percepción excitada por un color-masa, reintegra la materia a una realidad sumaria dejando al margen toda sospecha de referencialidad analógica. «¿Qué representa eso?», habrá quien diga. «Nada, lo que hay aquí sólo se presenta», será la respuesta. [...] Más allá del realismo, cuya representación resulta inevitable, lo que allí hay es una realidad presente (Salabert, 2017: 23).

Para Erika Martínez el compromiso consiste en la habilitación de un espacio entre, mestizo, un punto de encuentro de la intimidad con la extimidad -la presencia de la Cosa y del Otro en lo íntimo- del psicoanálisis (recuérdese: escribir concierne al tránsito). En este espacio un sujeto reconciliado con su singularidad y el palimpsesto espacio-temporal en el que está entreverado por obra de la restitución de las epistemes del cuerpo convive con una alteridad indómita y versátil, lo real, que precisamente consiente lo humano porque lo acota y desacota simultáneamente. Es el trasunto poético de lo que el filósofo británico Julian Baggini llama cuerpos de pensamiento: "Es el pensamiento —que incluye emociones y percepciones, no sólo procesos racionales— lo que nos hace quienes somos, pero estos pensamientos están siempre corporificados" porque "los cuerpos son esenciales, pero no son nuestra esencia” (Baggini, 2012: posición en Kindle 316-317). Y esos cuerpos de pensamiento son radicalmente políticos: otra pensadora, Judith Butler, afirma a través de la relectura de Hannah Arendt que "la acción política tiene lugar porque el cuerpo está presente", dándose "entre cuerpos, en un espacio que constituye la brecha entre mi cuerpo y el cuerpo de otros. Mi cuerpo, por tanto, no actúa en solitario cuando interviene en la política. De hecho, la acción emerge del entre" (Butler, 2017: 81).

En suma, la gramática del compromiso-investigación desplegada por Erika Martínez en Chocar con algo bien podría sintetizarse con estas palabras de Chantal Maillard en su reciente La razón estética: 
La palabra perdió desde hace tiempo su inmediatez. El discurso se genera corrientemente a partir de significados endurecidos bajo los cuales la realidad apenas late. La categoría de lo real ha sido transferida al concepto y muy rara vez somos capaces de recuperar en su singularidad la presencia viva de las cosas.

Hay, sin embargo, una modalidad del lenguaje en la que la palabra recupera la inmediatez y acierta a aprehender la traza de lo real haciéndose. Llamo "poesía fenomenológica» a aquel gesto del lenguaje que con la mínima expresión es capaz de manifestar el instante y hago extensiva la fórmula a la obra poética a la que tal gesto diese lugar. Expresión inmediata, sencilla, que capta las cosas entre su tiempo y su no-tiempo, entre su ser-objeto y su no-ser, en ese estarse-siendo del suceso en el que la mirada que capta y condensa la traza está implicada (Maillard, 2017: posición 3069-3076 en edición digital de Kindle).

Sin embargo, antes que Maillard otra pensadora, María Zambrano, había propuesto una tercera vía entre la hermenéutica -"El universo como tal no tiene Sentido. Es silencio. Nadie ha introducido el Sentido en el mundo. Sólo nosotros. El Sentido depende del ser humano, y el ser humano depende del Sentido" (Huston, 2017: posición 66-68 en edición digital de Kindle)- y la fenomenología -el ser en el mundo-. Convencida de la necesidad de superar la "obsesión de la legitimidad" de una razón instrumental caracterizada por una "sobreabundancia de ideas" que enmascara una desconexión con la realidad, que "se desliza, se hace fantasma de sí misma" (Zambrano, 2004: 22), Zambrano da forma a su rąón poética:

Necesidad de la respiración acompasada, necesidad de la convivencia, de no estar sola en un mundo sin vida; y de sentirla, no sólo con el pensamiento, sino con la respiración, con el cuerpo, aunque sea el minúsculo cuerpo de un pequeño animal, que respira: el sentir la vida, donde está y donde no está, o donde no está todavía. En ese "logos sumergido", en eso que clama por ser dentro de la razón (ibidem, 2004: 26).

Junto a la noción de entendimiento pasivo, la entrega "a la pasividad, a la sensibilidad, a la recepción" (ibidem, 2004: 27), la razón poética constituye una vía de acceso al conocimiento del mundo alternativa y complementaria al quehacer filosófico. Si este persigue lo universal, "en la poesía encontramos directamente al hombre concreto, individual", dado que la filosofía ha devenido "un género de mirada que ha dejado de ver las cosas", en tanto que la lírica "se quedó a vivir en los arrabales, arisca y desgarrada" y no olvida ese "pasmo ante lo inmediato", no desconfía de lo que no nos hurta su presencia y es capaz de entregarse a "un mundo abierto donde todo era posible. Los límites se alteraban de tal modo que acababa por no haberlos" (ibidem, 2004: 28-29). La poesía, por consiguiente, persigue "la multiplicidad despeñada, la menospreciada heterogeneidad. El poeta enamorado de las cosas se apega a ellas, a cada una de ellas y las sigue a través del laberinto del tiempo, del cambio, sin poder renunciar a nada. [...] La cosa del poeta no es jamás la cosa conceptual del pensamiento, sino la cosa complejísima y real" (ibidem, 2004: 29-30). En suma, Zambrano confía en el poema para combatir lo que denomina razón desencarnada, al igual que Erika Martínez.

Porque también en Martínez hay una alianza entre hermenéutica (no podemos volver a un mundo sin interpretación, no podemos no otorgar sentido, no podemos desandar el camino de la especulación -en el sentido literal: el mundo en su doble dimensión de ventana y espejo-, pero sí podemos explorar otras formas de sentido, de creación de conocimiento y significado que no pase por una realidad anoréxica) y fenomenología (ese sentido, empero, debe construirse desde la 
reconciliación con el afuera; de ahí el prestigio del cuerpo y el hermanamiento con lo espacial y objetual). Interpretación y asombro se vinculan entonces a través de una estética organoléptica en la que palabra e idea permanecen ancladas a sus contextos y circunstancias: "No estoy hablando de fantasmas: / el cuerpo acumula sus vivencias / a pesar de mi furor higiénico, se remonta años arriba o se demora. / No acepta despedidas. Me sucede" (Martínez, 2017: 49).

\section{CONCLUSIONES: EL COMPROMISO OBLICUO Y LAS NUEVAS EPISTEMES ARTÍSTICAS}

Entre la lírica que se resiste a abandonar la seguridad de las convenciones de la Modernidad (imperturbabilidad de sujeto, objeto y palabra como si nada hubiese pasado, a pesar de llegar a menudo de la mano de youtubers) y aquella que la niega desde la ruptura o el desbordamiento textual y desde el ensayo, más o menos afortunado o impostado, de fórmulas variopintas de impersonalidad y de colonización de la periferia del logos, Martínez se sitúa en territorio mestizo, presidido por la contingencia, la provisionalidad y una voluntad de indagación (interior y exterior) en la que el asombro (presocrático, casi de entomólogo) tiene más valor que la confirmación de hipótesis. A modo de recapitulación, enumeraremos a continuación algunos de los hitos que recorren el itinerario poético aquí esbozado:

- Volverse paisaje como modo de construir una subjetividad contingente y porosa. Cualquier manual de geografía nos recuerda que el territorio es el ambiente físico ajeno a la mirada del observador, que lo convierte en paisaje en cuanto este aparece en escena. No podemos desandar el camino emprendido por la aventura jonia y la irrupción de la teoría (theoría procede de theorós, espectador, el que mira desde la no implicación, desde una pretendida neutralidad y desinterés). De ahí que Martínez proponga una nueva ubicación epistémica y existencial (no la del conquistador, sino la del cuerpo entre cuerpos) y una nueva mirada (no la dicotómica racionalista, sino otra poliédrica, desplazada, vírica) en la que propiedades de sujeto y objeto se intercambian. Se funda así un éthos amable y osmótico, tanto en la acepción del sujeto que se muestra en un discurso abierto, en la palabra compartida, como en la de morada. Pero esa morada siempre está alerta ante el riesgo de constituirse en oikos bunkerizado, en espacio dogmático delimitado desde la exclusión, como recuerda la conocida imagen del astronauta de Sloterdijk: lo que nos protege puede aislarnos. De ahí la necesidad, subrayada por Erika Martínez, de mimar las experiencias de intemperie y nomadismo como prevención contra las identidades que se afirman en la negación del mundo.

- La centralidad y virtualidad politica del cuerpo vulnerable. En este proceso contra-místico o de relocalización de la vida, juega un papel fundamental el cuerpo, posibilidad de la experiencia de lo liminar, de una estética organoléptica que permite la vivencia no abstracta de espacio y tiempo y la interacción con otros cuerpos, biológicos o inertes. Experiencias como las de precariedad y vulnerabilidad, estudiadas por Judith Butler como articuladoras de una performatividad transgresora y subversiva (Butler, 2017), o la de fracaso, que en opinión de Jack Halberstam debe reivindicarse como refutación de la lógica competitiva de la acumulación capitalista (Halberstam, 2018) hacen aflorar el cuerpo, lo visibilizan, lo rescatan de la ilusión inmaterial y trascendente. Frente a la aventura del Espíritu, o de sus avatares digitales, el poema ofrece cuerpos dislocados. Pero una vez recuperado el cuerpo, aunque sea desde lo traumático, es posible la reconquista de una concepción relacional e interdependiente de la existencia, un paradigma ecológico de vida: "el cuerpo no es tanto una entidad como un conjunto de relaciones vivas; el cuerpo no puede ser separado del todo de las condiciones infraestructurales y ambientales" (Butler, 2017: 69). Es ese 
"carácter histórico del cuerpo", como lo denomina Butler, el que alumbra en el poema cierta voluntad escénica, la de visibilizar las tramas, la gramática de lo real, y su posible modificación.

- Cuerpo y paisaje exigen una escritura deíctica. Deixis, en su origen etimológico, significa tanto indicar, señalar, mostrar como revelar, sacar a la lu\%. En este artículo partimos de la acepción lingüística comúnmente aceptada y del procedimiento estudiado, entre otros, por Émile Benveniste en relación con las formas pronominales, esto es, el "conjunto de «signos vacíos» $[. .$.$] que se vuelven llenos no bien un locutor los asume en cada instancia de su$ discurso" (Benveniste, 1997: 75). Como bien señala Luis J. Eguren, "los deícticos no sólo identifican entidades de primer orden (personas, animales y objetos), sino también entidades de segundo orden (acontecimientos, situaciones y estados de cosas que se producen o existen en el mundo físico)", de manera que presentan "una naturaleza híbrida: utilizando una terminología propia de la semiótica, son a la vez «símbolos»e «úndices»" (Eguren, 1999: 932-933). Es esa condición jánica de lo deíctico la que nos anima a desplazar este calificativo a una poesía exofórica, como la de Martínez, en la que la atención a lo contextual no es óbice para la proposición de sentidos alternativos en el universo de lo textual. "La poesía no es autónoma. La realidad tampoco" (Martínez, 2013b: 64), por lo que el poeta no ha de elegir entre el exilio interior de la metaliteratura y las naturalezas muertas de un mimetismo documentalista. Los rasgos de esta escritura deliberadamente circunstancial y arraigada son a) una escritura que no rehúsa su función referencial: hay que dar cuenta del mundo, aunque de un mundo en el que texto y contexto, poesía y realidad, están felizmente amalgamados, y desde modos de representación tangenciales, oblicuos; b) una escritura dialógica, sabedora de su condición discursiva y transaccional, más babla que lengua en términos saussurianos, y performativa, que aúna comunicación y acción; y c) una escritura descreída de la mitificación de la persona como instancia otorgadora de sentido: las formas pronominales sólo existen fugazmente en el seno del discurso y necesitan del anclaje en lo real, en un cuerpo que interactúa con otros cuerpos en lugares y momentos concretos.

El esfuerzo de Erika Martínez por llevar a la poesía más allá del arresto domiciliario al que la tiene sometida el capitalismo estético no puede entenderse sin considerar los giros epistemológicos acontecidos en las artes en las últimas décadas. En los textos de Martínez es manifiesta la huella de la reorientación pragmática de un lenguaje que no renuncia a la enunciación de una verdad dialógica y dialéctica; el llamado giro espacial y su deseo de mantener la "atadura entre lenguaje, lugar y tiempo", de potenciar lo que el geógrafo norteamericano Edward Soja llama la imaginación crítica espacial, "en lo que tiene de capacidad reconfiguradora desde el señalamiento" y de "voluntad constructiva", o la dignificación del cuerpo "como lugar de cruce" de los tres espacios señalados por Lefebvre -el concebido, el percibido y el vivido(Quesada, 2016: 165, 167, 170); o los feminismos que contribuyen a la problematización del binarismo "sistema sexo/género, yo/otro" y "al desvanecimiento y transgresión de las fronteras en tránsito hacia los espacios liminares" (Sainza, 2016: 264, 267). Y estos giros epistemológicos sugieren rupturas más ambiciosas, como las apuntadas por François Jullien: nuevas formas de inteligibilidad desde estructuras no narrativas (míticas o épicas); la concepción del mundo sin esencialismos, como dispositivo, "en términos de «capacidad» práctica"; heterodoxas fórmulas de conocimiento que no tratan de acotar y cercar el objeto, desde un desbroce que es a menudo acorralamiento y descontextualización, sino "de forma sesgada", desde acercamientos oblicuos (la "distancia alusiva"); un prestigio de la inmanencia, del "asi de las cosas"; y una concepción 
relacional de lo real frente a nuestra noción "individualizante, aislante, atomizante" (Jullien, 2005: $4,7,9,33)$.

Martínez es capaz de construir un poema que guarda similitud con el tercer paisaje de Gilles Clément: espacio residual, de transición, en el que lo natural y lo antrópico se confunden (Clément, 2014). Porque ese tercer paisaje textual es el único que permite la suspicacia, la crítica como responsabilidad, la ambivalencia, la orfandad, la distancia irónica y la desubicación, rasgos todos que Martínez asocia a lo que llama poesía portátil -por lo que tiene de nómada- y viscosa porque "ensucia, deja huella"- (Martínez, 2013b: 52-53). 


\section{BIBLIOGRAFÍA}

BAgGINI, Julian (2012). La trampa del ego: Qué significa ser tú. Barcelona: Paidós.

Bagué Quílez, Luis (2006). Poesía en pie de paz: Modos del compromiso hacia el tercer milenio. Valencia: Pre-Textos.

Benasayag, Miguel y Del ReY, Angélique (2014). El compromiso en una época oscura. Madrid: Tierradenadie Ediciones.

Benjamin, Walter (2011). Libro de los Pasajes. Madrid: Akal.

BENVEnISTE, Émile (1997). Problemas de Lingüistica General, volumen I. Madrid: Siglo XXI.

ButLer, Judith (2017). Cuerpos aliados y lucha politica. Hacia una teoria performativa de la asamblea. Barcelona: Paidós.

ClÉMENT, Gilles (2018). Manifiesto del tercerpaisaje. Barcelona: Gustavo Gili.

Didi-Huberman, Georges (1997). Lo que vemos, lo que nos mira. Buenos Aires: Ediciones Manantial.

EGuREN, Luis J. (1999). "Pronombres y adverbios demostrativos. Las relaciones deícticas". Bosque, Ignacio y Demonte, Violeta (eds.). Gramática descriptiva de la lengua española. Madrid: Espasa Calpe / Real Academia Española: 929-972.

EsPosito, Roberto (2016). Las personas y las cosas. Buenos Aires: Katz Editores.

GARCÉS, Marina (2017). Nueva ilustración radical. Barcelona: Anagrama.

GARCÍA, Miguel Ángel (ed.) (2017). El canon del compromiso en la poesía española contemporánea. Antologias y poemas. Madrid: Visor Libros.

García-Teresa, Alberto (2013). Poesía de la conciencia crítica (1987-2011). Madrid: Tierradenadie Ediciones.

HALBERSTAM, Jack (2018). El arte queer del fracaso. Barcelona-Madrid: editorial Egales.

Huston, Nancy (2017). La especie fabuladora. Barcelona: Galaxia Gutenberg.

IraVedra, Araceli (2010). El compromiso después del compromiso. Poesía, democracia y globalización (poéticas 1980-2005). Madrid: UNED.

Jullien, François (2005). La China da que pensar. Barcelona: Anthropos.

LeCHNER, Jan (2004). El compromiso en la poesía española del siglo XX. Alicante: Publicaciones de la Universidad de Alicante.

MAILLARD, Chantal (2017). La razón estética. Barcelona: Galaxia Gutenberg.

MartíneZ, Erika (2009). Color carne. Valencia: Pre-Textos.

MARTíneZ, Erika (2011). Lenguaraz: Valencia: Pre-Textos.

MArtíneZ, Erika (2013a). El falso techo. Valencia: Pre-Textos. 
MARTíneZ, Erika (2013b). "Valores portátiles. El sujeto bajo crítica". BAGUÉ QuíLEZ, Luis y SANTAMARÍA Alberto (eds.). Malos tiempos para la épica. Última poesía española (2001-2012). Madrid: Visor Libros: 49-64.

MArTíneZ, Erika (2017). Chocar con algo. Valencia: Pre-Textos.

MÉndez Rubio, Antonio (2013). La destrucción de la forma ( $Y$ otros escritos sobre poesía y conflicto). Madrid: Biblioteca Nueva.

Moreno, Javier (2013). “Ciencia y lenguaje”. BAguÉ Quílez, Luis y SANTAMARíA Alberto (eds.). Malos tiempos para la épica. Última poesía española (2001-2012). Madrid: Visor Libros: 221-238.

QuesadA, Fernando (2016). "El giro espacial. Conquista y fetiche”. CONDERANA, José Alberto (coord.). Giros epistemológicos de las artes. La creación de significado. Madrid: Ediciones Asimétricas: 165-187.

SAINZA, Bárbara (2016). "Heteroglosia como eje epistemológico. Perspectivas feministas". ConderanA, José Alberto (coord.). Giros epistemológicos de las artes. La creación de significado. Madrid: Ediciones Asimétricas: 261-280.

SALABERT, Pere (2017). El pensamiento visible. Madrid: Akal.

Sánchez García, Remedios (2015). Humanismo solidario. Poesía y compromiso en la sociedad contemporánea. Madrid: Visor Libros.

Zambrano, María (2004). Breve antología. Granada: Junta de Andalucía. Consejería de Cultura. 